Check for updates

Cite this: RSC Adv., 2019, 9, 5918

\title{
Irreversible catalytic methylcyclohexane dehydrogenation by surface protonics at low temperature $\dagger$
}

\author{
Kent Takise, ${ }^{a}$ Ayaka Sato, ${ }^{a}$ Kota Murakami, ${ }^{a}$ Shuhei Ogo, (D) a Jeong Gil Seo, (D) ab \\ Ken-ichi Imagawa, ${ }^{c}$ Shigeru Kado ${ }^{c}$ and Yasushi Sekine (D) *a
}

Liquid organic hydrides are regarded as promising for use as hydrogen carriers via the methylcyclohexane $(\mathrm{MCH})$-toluene-hydrogen cycle. Because of the endothermic nature of $\mathrm{MCH}$ dehydrogenation, the reaction is usually conducted at temperatures higher than $623 \mathrm{~K}$. In this work, low-temperature catalytic $\mathrm{MCH}$ dehydrogenation was demonstrated over $3 \mathrm{wt} \% \mathrm{Pt} / \mathrm{CeO}_{2}$ catalyst by application of electric field across a fixed-bed flow reactor. Results show that a high conversion of $\mathrm{MCH}$ beyond thermodynamic equilibrium was achieved even at $423 \mathrm{~K}$. Kinetic analyses exhibited a positive correlation of hydrogen to the reaction rates and an "inverse" kinetic isotope effect (KIE), suggesting that accelerated proton hopping with the $\mathrm{H}$ atoms of $\mathrm{MCH}$ promotes the reaction. Operando analyses and DFT calculation proved that the reverse reaction (i.e. toluene hydrogenation) was suppressed by the facilitation of toluene desorption in the electric field. The electric field promoted $\mathrm{MCH}$ dehydrogenation by surface proton hopping, even at low temperatures with an irreversible pathway.

Received 17th January 2019

Accepted 10th February 2019

DOI: $10.1039 / c 9 r a 00407 f$

rsc.li/rsc-advances endothermic reaction, as shown in eqn (1). It is normally conducted at reaction temperatures higher than $623 \mathrm{~K}$ due to its kinetic and thermodynamic limitations. ${ }^{5}$

$$
\mathrm{C}_{7} \mathrm{H}_{14} \rightarrow \mathrm{C}_{7} \mathrm{H}_{8}+3 \mathrm{H}_{2}, \Delta H_{298}^{0}=204.8 \mathrm{~kJ} \mathrm{~mol}^{-1}
$$

Various Pt-supported catalysts have been investigated extensively because of their high activity and selectivity for $\mathrm{MCH}$ dehydrogenation. ${ }^{5,8}$ However, Pt-supported catalysts are reported as easily deactivated with toluene fouling and coke deposition..$^{9-15}$ Many studies assessing the prevention of fouling and coke have been conducted., ${ }^{4,6,7,16-19}$ Catalyst stability is important to achieve adequate cost-effectiveness of the organic hydride system. Lowering the dehydrogenation temperature is also very important, because it can reduce energy consumption, and enables use of low-grade heat., ${ }^{5,20-22}$ Nevertheless, the dehydrogenation reaction is limited strongly by the thermodynamic equilibrium, especially at low temperatures. To exceed this equilibrium limitation, several attempts have been examined using catalytic membrane reactors, ${ }^{23-29}$ liquid-film-type catalyst $^{30-34}$ and wet-dry multiple phase condition. ${ }^{35,36}$ Imposition of an electric field also promotes endothermic catalytic reactions at low temperatures. ${ }^{37-44}$ Manabe and co-workers reported that methane steam reforming proceeded, exceeding equilibrium limitations in an electric field at $423 \mathrm{~K}$ because of an irreversible reaction mechanism. ${ }^{37}$ Hopping proton over electric-field-imposed $\mathrm{Pd} / \mathrm{CeO}_{2}$ plays an important role, ${ }^{37,45}$ and hydrogen can be obtained even at low temperatures by proton hopping. ${ }^{36,37,45}$ This is the first report that electric field 
application enables catalytic $\mathrm{MCH}$ dehydrogenation at low temperature $(423 \mathrm{~K})$ with high conversion; exceeding the equilibrium limitation by a surface proton hopping.

\section{Experimental}

\subsection{Catalyst preparation}

$\mathrm{Pt} / \mathrm{CeO}_{2}$ catalyst was prepared using a wet-impregnation method. Catalyst support $\mathrm{CeO}_{2}$ (JRC-CEO-1) was impregnated with a solution of $\mathrm{Pt}\left(\mathrm{NH}_{3}\right)_{4}\left(\mathrm{NO}_{3}\right)_{2}$ (Sigma-Aldrich Corp.). $\mathrm{CeO}_{2}$ support was soaked in $25 \mathrm{~mL}$ of water for $2 \mathrm{~h}$. Then, Pt precursor was added with $15 \mathrm{~mL}$ of water and was stirred for $2 \mathrm{~h}$ using an evaporator. The loading amount of Pt was adjusted to $3 \mathrm{wt} \%$. The solution was dried up. Then the resultant powder was calcined at $773 \mathrm{~K}$ for $2 \mathrm{~h}$. The obtained catalyst was sieved to $355-500 \mu \mathrm{m}$.

\subsection{Catalytic activity tests}

Catalytic activity tests were conducted with a fix-bed flow type reactor in which $200 \mathrm{mg}$ of $\mathrm{Pt} / \mathrm{CeO}_{2}$ catalyst was charged. Two stainless steel electrodes were inserted contiguously on the upper-side and bottom-side of the catalyst-bed to impose an electric field (see ESI Fig. S1†). The same setup was used also for the reaction without the electric field. For reaction in the electric field, $3.0 \mathrm{~mA}$ of constant current was applied between two electrodes. The reaction temperatures were set respectively to 423 and $523 \mathrm{~K}$ for reactions with and without the electric field. The reaction gas composition was $\mathrm{C}_{7} \mathrm{H}_{14}: \mathrm{Ar}=6.4: 30$ and the

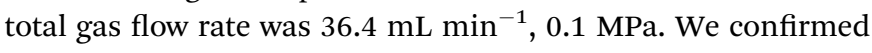
that the reaction condition is in a kinetic region at lower temperatures, and confirmed that diffusion is not a ratedetermining factor (Fig. S2 $\dagger$ ). The reaction was conducted for $480 \mathrm{~min}$ to confirm the catalytic stability for $\mathrm{MCH}$ dehydrogenation. The product gas of the reaction was measured using GCFID (GC-8A; Shimadzu Corp.) and GC-TCD (GC-8A; Shimadzu Corp.). Hydrogen yield was defined with the $\mathrm{MCH}$ feed rate $\left(\mu \mathrm{mol} \mathrm{min}{ }^{-1}\right)$ and the $\mathrm{H}_{2}$ formation rate $\left(\mu \mathrm{mol} \mathrm{min}{ }^{-1}\right)$. The resultant liquid during the reaction was analyzed using GC-FID (GC-4000; GL Science Inc.).

$$
\text { Hydrogen yield }(\%)=r_{\mathrm{H}_{2}} /\left(\mathrm{C}_{7} \mathrm{H}_{14} \text { feed rate } \times 3\right) \times 100
$$

Arrhenius plots were obtained over $\mathrm{Pt} / \mathrm{CeO}_{2}$ catalyst to evaluate the apparent activation energy of $\mathrm{MCH}$ dehydrogenation with and without the electric field in a kinetic condition. Reaction rates were evaluated in kinetic control. In fact, the reaction rates were defined from the formation rate of $\mathrm{H}_{2}$ in the same manner as that used for activity tests. For a reaction with the electric field, the catalyst temperature was increased with Joule heating from the imposed electricity. Therefore, a thermocouple was inserted to the catalyst bed. It monitored the actual temperature of the catalyst.

After reaction for $480 \mathrm{~min}$, the coke deposited on the catalyst was found from temperature-programmed oxidation (TPO) measurements obtained using a gas chromatograph to estimate $\mathrm{CO}$ or $\mathrm{CO}_{2}$ formation by coke oxidation. The temperature was increased from $298 \mathrm{~K}$ to $1173 \mathrm{~K}$ at $10 \mathrm{~K} \mathrm{~min}^{-1}$ in the gas composition of $\mathrm{O}_{2}: \mathrm{He}=10: 90\left(\mathrm{~mL} \mathrm{~min}^{-1}\right)$. The produced gas components and coke formation amount met a conceivable mass balance, i.e. almost $100 \%$.

\subsection{Partial pressure dependence and isotope effect}

To elucidate the reaction mechanism, the dependence of partial pressure and reaction rate was evaluated for $\mathrm{MCH}$, toluene, and hydrogen in each reaction condition because $\mathrm{MCH}$ conversion showed almost equal levels for these two cases: (1) at $423 \mathrm{~K}$ with the electric field and (2) at $523 \mathrm{~K}$ without the electric field. The feed gas composition was modified as $\mathrm{C}_{7} \mathrm{H}_{14}: \mathrm{Ar}=(3.2,6.4,9.6$, 11.3) : (53.2, 50.0, 46.8, 45.1), $\mathrm{C}_{7} \mathrm{H}_{14}: \mathrm{C}_{7} \mathrm{H}_{8}: \mathrm{Ar}=6.4:(1.0,2.0$, 3.0, 4.0) : (49.0, 48.0, 47.0, 46.0) and $\mathrm{C}_{7} \mathrm{H}_{14}: \mathrm{H}_{2}: \mathrm{Ar}=6.4:(4.0$, $7.0,9.0,12.0):(46.0,43.0,41.0,38.0)$. The total gas flow rate was $56.4 \mathrm{~mL} \mathrm{~min}{ }^{-1}, 0.1 \mathrm{MPa}$. Reaction rates were calculated from the formation rate of $\mathrm{H}_{2}$ analyzed using GC-TCD (GC-8A; Shimadzu Corp.).

To elucidate the isotope effects of $\mathrm{MCH}$ dehydrogenation reaction, isotopes of $\mathrm{MCH}$ and $\mathrm{H}_{2}$ were used. The feed gas composition was modified as $\mathrm{C}_{7} \mathrm{H}_{14}\left(\right.$ or $\left.\mathrm{C}_{7} \mathrm{D}_{14}\right): \mathrm{H}_{2}\left(\right.$ or $\left.\mathrm{D}_{2}\right): \mathrm{Ar}$ $=6.4: 4.0: 46.0$. The total gas flow rate was $56.4 \mathrm{~mL} \mathrm{~min}^{-1}$. Reaction rates were calculated from the formation rate of $\mathrm{H}_{2}$, $\mathrm{HD}$, and $\mathrm{D}_{2}$.

\subsection{Operando DRIFTS measurements}

To observe the surface state of $\mathrm{Pt} / \mathrm{CeO}_{2}$ catalyst in the electric field, DRIFTS measurements were conducted using a Fourier transform infrared spectrometer (FT/IR-6100; Jasco Corp.). Additionally, measurement apparatus was assembled for application of the electric field to the samples as described in an earlier report of the relevant literature. ${ }^{45}$ In this experiment, sieved catalyst was used. Two Pt electrodes were set on the catalyst. First, to confirm the state of the adsorbed species on Pt/ $\mathrm{CeO}_{2}$ catalyst during the reaction, operando DRIFTS measurements were conducted. This operando measurement was conducted with the electric field at $423 \mathrm{~K}$ and without electric fields at 423 and $523 \mathrm{~K}$. For measurements with the electric field, the constant current was imposed after the $\mathrm{MCH}$ introduction. Second, to observe the time course behavior of the absorbed species of MCH, intermediates, and toluene, DRIFTS measurements were taken with the electric field at $423 \mathrm{~K}$ and without the electric field at $523 \mathrm{~K}$. For these measurements, $\mathrm{MCH}$ was supplied for 5 min into the measurement vessel to adsorb $\mathrm{MCH}$ on the catalyst. Subsequently, the gas flow was switched to Ar during measurement. Constant current was imposed immediately after the gas switching to Ar. Subsequently, IR spectra were observed for $60 \mathrm{~min}$ in each condition.

\subsection{Hydrogenation of toluene}

Regarding the investigation of toluene hydrogenation activity on $\mathrm{Pt} / \mathrm{CeO}_{2}$ catalyst, the reaction was conducted with and without the electric field. The feed gas composition was $\mathrm{C}_{7} \mathrm{H}_{8^{-}}$ $: \mathrm{H}_{2}: \mathrm{Ar}=6.4: 19.2: 10.8$ (molar ratio). The total gas flow was $36.4 \mathrm{~mL} \mathrm{~min}^{-1}, 0.1 \mathrm{MPa}$. The product liquid during the reaction was measured using GC-FID (GC-4000; GL Science Inc.). 


\subsection{Characterization}

Dispersion and metal surface area of Pt metal was estimated using CO pulse measurements (BELCAT II; MicrotracBEL Corp.). Pre-treatment was conducted at $623 \mathrm{~K}$ in $\mathrm{He}$ gas to vaporize the adsorbed water. In addition, the state of supported Pt was confirmed with STEM images and EDX mapping results from scanning transmission electron microscopy (STEM; HF2210; Hitachi Ltd.). The specific surface area of the catalyst was investigated based on $\mathrm{N}_{2}$ adsorption using the BET method (Gemini VII; Micromeritics Instrument Corp.). Pre-treatment was conducted at $473 \mathrm{~K}$ in a $\mathrm{N}_{2}$ atmosphere for $2 \mathrm{~h}$.

\subsection{First-principles calculation}

Theoretical analysis for vibrational spectral analysis was conducted using DFT calculations. All calculations were conducted using the Vienna ab initio simulation package (VASP) ver. 5.4.1. Procedure is described in ESI. $\dagger$

\section{Results and discussion}

\subsection{Catalytic activity and the proton hopping role in the electric field}

We conducted $\mathrm{MCH}$ dehydrogenation over $3 \mathrm{wt} \% \mathrm{Pt} / \mathrm{CeO}_{2}$ at temperatures of $423-573 \mathrm{~K}$ to confirm the electric field effects at low temperature range. $3 \mathrm{wt} \% \mathrm{Pt} / \mathrm{CeO}_{2}$ catalyst is an excellent catalyst for this purpose in an electric field, as confirmed from our pre-screening test (60 catalysts with various metals and supports are tested, not shown). Catalytic activities in terms of $\mathrm{H}_{2}$ yield and the $\mathrm{CH}_{4}$ production rate at each temperature are presented in Table 1 . All the tests are conducted in a kinetic region (i.e. lower conversion condition). The actual temperature of catalyst was increased by Joule heating of the imposed electricity. Although the increase of temperature was $19 \mathrm{~K}$ at most $(423 \mathrm{~K})$, the catalytic activity was strongly promoted from $0.8 \%$ to $21.6 \%$ in the electric field. The conversion in the electric field can be increased to higher value by changing the contact time as shown in Fig. S2. $\dagger$ Consequently, the Joule heat effects on the catalytic activity are negligible. The catalyst activity was affected considerably by the applied electric field in the lower temperature range. Notably, the catalytic activity (21.6\%) at $423 \mathrm{~K}$ with the electric field, which exceeds the equilibrium limitation $(=5.5 \%)$ at this temperature. In terms of the methane (byproduct) production rate, the catalyst in the electric field showed a lower methane production rate than the catalyst without an electric field at a similar catalytic activity level. In other words, applying an electric field to the catalyst facilitated dehydrogenation and suppressed $\mathrm{MCH}$ decomposition. To confirm this facilitative effect for dehydrogenation, Arrhenius plots are presented for kinetic region for both cases, i.e. with and without the electric field (Fig. 1). The apparent activation energy was $55.6 \mathrm{~kJ} \mathrm{~mol}^{-1}$ without the electric field, whereas it was $28.6 \mathrm{~kJ} \mathrm{~mol}^{-1}$ with the electric field. These results suggest that the $\mathrm{MCH}$ dehydrogenation was strongly promoted with electric field imposition. This phenomenon shows that the reaction mechanism on the catalysis in the electric field is completely different from that on the heated catalyst. To elucidate the reaction mechanism, the dependence of partial pressure and reaction rate for $\mathrm{MCH}$, toluene, and hydrogen was evaluated over $\mathrm{Pt} / \mathrm{CeO}_{2}$ catalyst with the electric field at $423 \mathrm{~K}$ and without the electric field at $523 \mathrm{~K}$, as presented in Fig. 2. Here, the reaction rate of $\mathrm{MCH}$ dehydrogenation is defined as described in eqn (3) with each partial pressure.

$$
r_{\text {Dehydrogenation }}=k[\mathrm{MCH}]^{a}[\text { toluene }]^{b}\left[\mathrm{H}_{2}\right]^{c}
$$

Generally, toluene and hydrogen partial pressures negatively affect the reaction rates of $\mathrm{MCH}$ dehydrogenation because toluene adsorption competitively inhibits adsorption of $\mathrm{MCH}$ to the reaction site. As Fig. 2 shows, the partial pressures of toluene and hydrogen are negatively correlated with the reaction rates without the electric field (i.e. heated catalyst). ${ }^{5}$ Although toluene partial pressures are also negatively correlated with the reaction rate in the electric field, the order of correlation slope increased from -0.18 (without the electric field) to -0.07 (with the electric field). Moreover, the partial pressure of hydrogen was positively correlated with dehydrogenation reaction in the electric field, which is an extraordinary phenomenon considering the nature of hydrogenation reactions (i.e. normally reversible). We found in earlier studies that proton hopping on the catalyst enables low-temperature catalysis in many cases. In such cases, hydrogen partial pressure dependence shows positive values. ${ }^{37-39}$ Therefore, $\mathrm{H}$ species are considered to promote dehydrogenation of $\mathrm{MCH}$ on the $\mathrm{Pt} / \mathrm{CeO}_{2}$ in an electric field.

To confirm the role of $\mathrm{H}$ species in the electric field, isotope effects were investigated supplying isotope $\mathrm{MCH}_{\mathrm{D}}$ (i.e. $\mathrm{C}_{7} \mathrm{D}_{14}$ ) and $\mathrm{D}_{2}$ to the catalyst with and without the electric field (Table $2)$. Isotope effects were defined as $k_{\mathrm{D}} / k_{\mathrm{H}}$, where $k$ is the rate constant of dehydrogenation calculated from the hydrogen

Table 1 Temperature dependencies of catalytic activity in a kinetic condition on $3 \mathrm{wt} \% \mathrm{Pt} / \mathrm{CeO}_{2}$ with and without the electric field; gas supply:

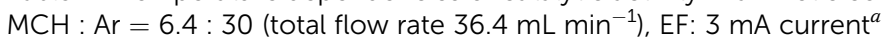

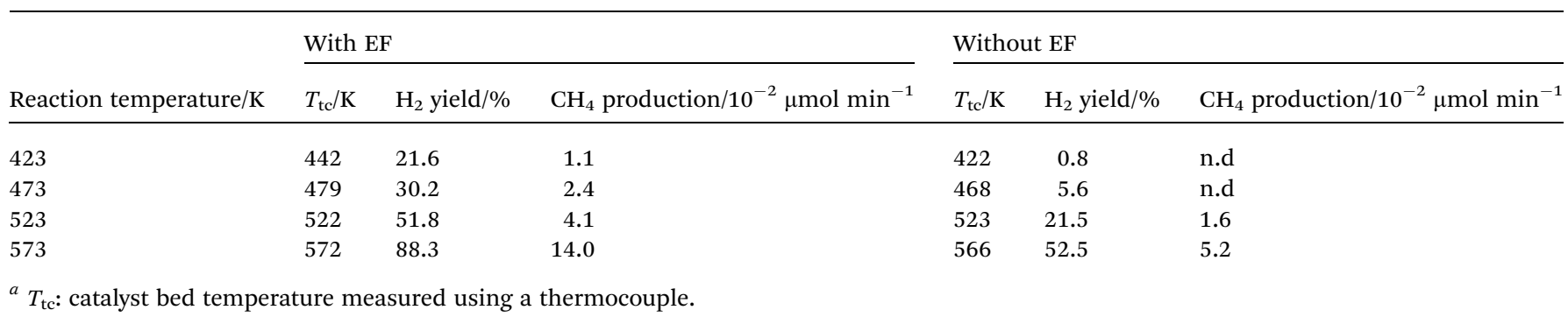




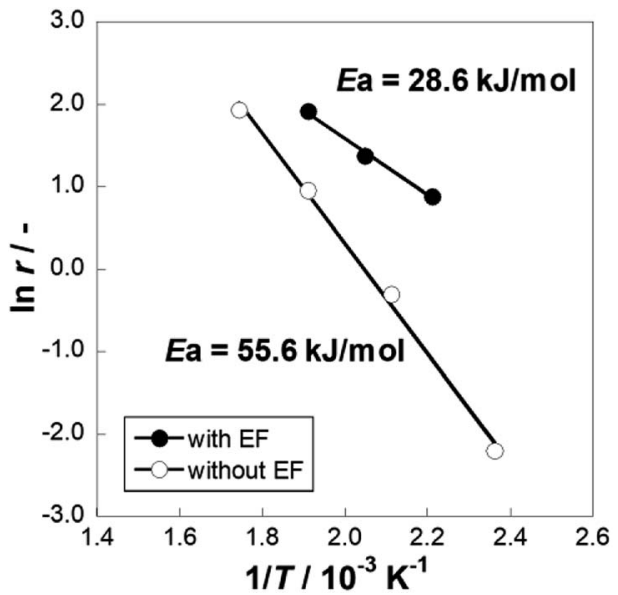

Fig. 1 Arrhenius plots for 3 wt\% Pt/CeO 2 catalyst with and without the electric field (EF): gas supply, $\mathrm{MCH}: \mathrm{Ar}=6.4: 30$ (total flow rate 36.4 $\mathrm{mL} \mathrm{min}^{-1}$ ); EF: current $3 \mathrm{~mA}$.
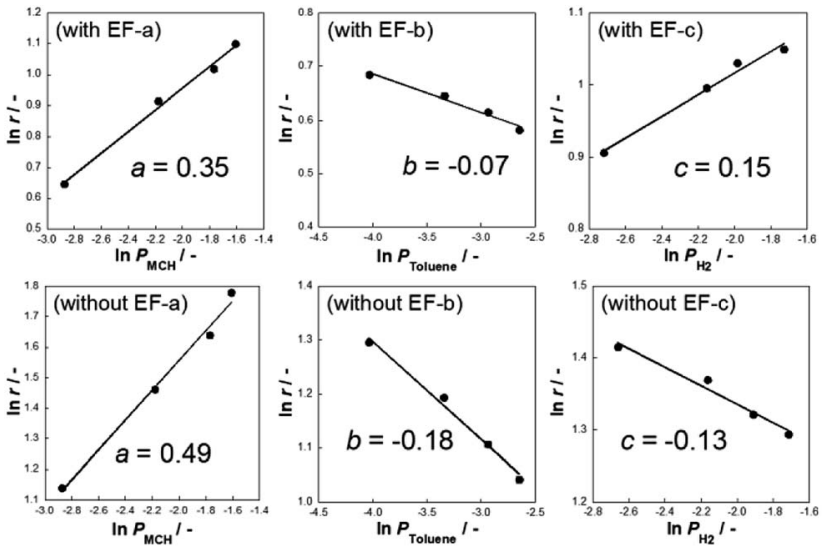

Fig. 2 Dependence of partial pressure and reaction rate for (a) methylcyclohexane, (b) toluene, and (c) hydrogen over $3 \mathrm{wt} \% \mathrm{Pt} / \mathrm{CeO}_{2}$ in methylcyclohexane dehydrogenation with the electric field at $423 \mathrm{~K}$ and without electric field at $523 \mathrm{~K}$; current $3 \mathrm{~mA}$.

formation rate in a kinetic region. Without the electric field, the $k_{\mathrm{D}} / k_{\mathrm{H}}$ value was lower than 1.0 when $\mathrm{MCH}_{\mathrm{D}}$ was supplied: 0.67 and 0.69 for $\mathrm{MCH}_{\mathrm{D}} / \mathrm{H}_{2}$ and $\mathrm{MCH}_{\mathrm{D}} / \mathrm{D}_{2}$ cases, respectively. Furthermore, reaction rates were unaffected by the exchange of
$\mathrm{H}_{2}$ and $\mathrm{D}_{2}$. In most cases, chemical bonds including heavier isotopes require higher dissociation energy because of the stability of zero-point energy (ZPE), which leads to a lower kinetic value of the reaction $\left(k_{\mathrm{D}} / k_{\mathrm{H}}<1\right)$. Thereby, kinetic isotope effect (KIE) was observed during the reaction without the electric field. However, $k_{\mathrm{D}} / k_{\mathrm{H}}$ values with the electric field were increased; $k_{\mathrm{D}} / k_{\mathrm{H}}$ were $1.20,1.22$, and 1.42 for $\mathrm{MCH}_{\mathrm{D}} / \mathrm{H}_{2}, \mathrm{MCH}_{\mathrm{H}} /$ $\mathrm{D}_{2}$, and $\mathrm{MCH}_{\mathrm{D}} / \mathrm{D}_{2}$, respectively. These "inverse" KIE were observed when a $\mathrm{C}-\mathrm{H}-\mathrm{H}$ configuration is formed with proton collision because the three-atom transition state has greater discrepancy of ZPE between isotopes than the physisorption state. ${ }^{45-51}$ From kinetic isotope analyses, $\mathrm{MCH}$ dehydrogenation is promoted by proton collision in the electric field.

\subsection{Observation of adsorbed species and reaction mechanism on $\mathrm{Pt} / \mathrm{CeO}_{2}$ in the electric field}

Operando IR measurements were conducted over $\mathrm{Pt} / \mathrm{CeO}_{2}$ catalyst to confirm the role of accelerated protons in $\mathrm{MCH}$ dehydrogenation. Fig. 3 portrays the operando IR spectrum during MCH gas supply with the electric field at $423 \mathrm{~K}$, without the electric field at $423 \mathrm{~K}$, and also without the electric field at $523 \mathrm{~K}$. Without the electric field, two peaks for $\mathrm{C}-\mathrm{H}$ stretching vibrations were observed, respectively, at 2925 and $2938 \mathrm{~cm}^{-1}$, assigned to $-\mathrm{CH}_{3}$ and $-\mathrm{CH}_{2}$ - of physisorbed $\mathrm{MCH}$ (Fig. S3 $\dagger$ ). ${ }^{52,53}$ In addition, doublet peaks of $\mathrm{C}-\mathrm{H}$ stretching were confirmed around $2860 \mathrm{~cm}^{-1} .{ }^{52,53}$ Regarding peaks with the electric field, there were four peaks in the $\mathrm{C}-\mathrm{H}$ stretching region: 2910, 2925, 2938 , and $2953 \mathrm{~cm}^{-1}$. The peak intensity of the formed toluene was negligible compared to that of MCH (Fig. S4†). Thereby, peculiar peaks for the spectra in the electric field were detected at 2910 and $2953 \mathrm{~cm}^{-1}$.

For the specification of such peculiar peaks in the electric field, DFT calculations were done. This first-principles calculation considered the physisorption state of $\mathrm{MCH}\left(\mathrm{C}_{7} \mathrm{H}_{14}\right)$ and chemisorption states of $\mathrm{C}_{7} \mathrm{H}_{13}$ species. According to kinetic analyses, $\mathrm{MCH}$ dehydrogenation was promoted by proton collision in the electric field. In this case, $\mathrm{C}_{7} \mathrm{H}_{13}$ species could be formed after the first proton collision to $\mathrm{MCH}$ with production of $\mathrm{H}_{2}$. The most stable structures and adsorption energies were calculated for $\mathrm{MCH}$ physisorption and $\mathrm{C}_{7} \mathrm{H}_{13}$ chemisorption states (Fig. 4). Consequently, chemisorption on the $\gamma$-position

Table $2 \mathrm{MCH}$ dehydrogenation using isotope; 3 wt\% $\mathrm{Pt} / \mathrm{CeO}_{2}$ catalyst; gas supply $\mathrm{MCH}: \mathrm{H}_{2}\left(\right.$ or $\mathrm{D}_{2}$ ) : Ar = $6.4: 4: 46$ (total flow rate 56.4 $\mathrm{mL}$ min $^{-1}$ ); EF: 3 mA current ${ }^{a}$

\begin{tabular}{|c|c|c|c|c|c|}
\hline Condition & & $T_{\mathrm{tc}} / \mathrm{K}$ & $\mathrm{H}_{2}$ production rate $/ \mu \mathrm{mol} \mathrm{min}^{-1}$ & $\mathrm{H}_{2}$ yield/\% & $k_{\mathrm{D}} / k_{\mathrm{H}} /-$ \\
\hline \multirow[t]{3}{*}{ With EF (423 K) } & $\mathrm{MCH}_{\mathrm{H}} / \mathrm{H}_{2}$ & 445 & 148 & 18.8 & - \\
\hline & $\mathrm{MCH}_{\mathrm{H}} / \mathrm{D}_{2}$ & 441 & 178 & 22.6 & 1.20 \\
\hline & $\mathrm{MCH}_{\mathrm{D}} / \mathrm{D}_{2}$ & 442 & 209 & 26.6 & 1.42 \\
\hline \multirow[t]{2}{*}{ Without EF (523 K) } & $\mathrm{MCH}_{\mathrm{H}} / \mathrm{H}_{2}$ & 519 & 247 & 31.5 & - \\
\hline & $\mathrm{MCH}_{\mathrm{H}} / \mathrm{D}_{2}$ & 519 & 255 & 32.5 & 1.03 \\
\hline
\end{tabular}

${ }^{a} T_{\text {tc }}$ : catalyst bed temperature measured using a thermocouple. 


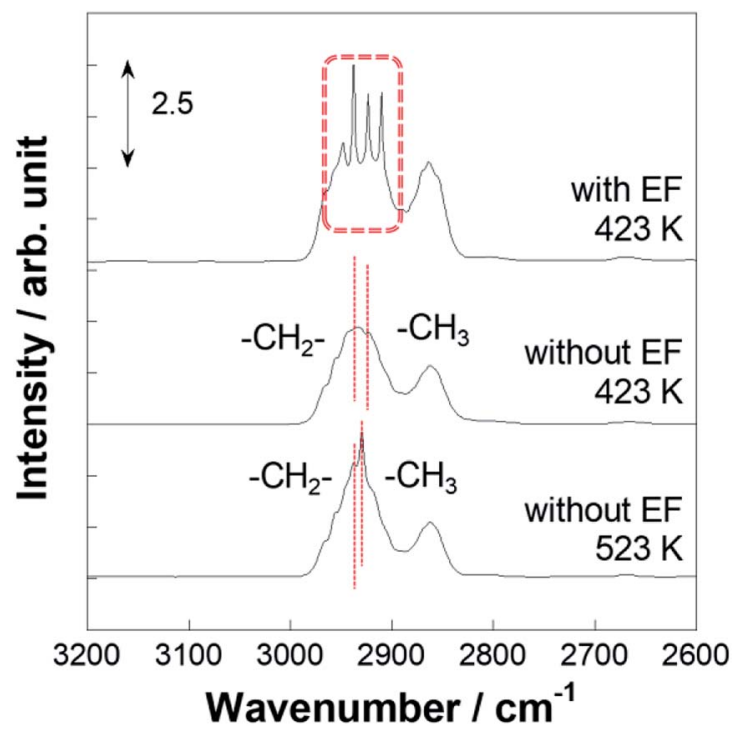

Fig. 3 Operando DRIFTS spectra for 3 wt\% $\mathrm{Pt} / \mathrm{CeO}_{2}$ with the electric field at $423 \mathrm{~K}$ and without the electric field at 423 and $523 \mathrm{~K}$.

or $\delta$-position was more stable, but all chemisorption states were able to be formed in view of the calculated adsorption energies. For that reason, theoretical $\mathrm{C}-\mathrm{H}$ stretching vibrations were calculated to assign those peaks. As results of the calculations (Fig. S5†), peaks at 2910 and $2953 \mathrm{~cm}^{-1}$ can be attributed respectively to $\mathrm{C}_{7} \mathrm{H}_{13}$ chemisorption with the $\beta$-position and $\delta$ position. These $\mathrm{C}_{7} \mathrm{H}_{13}$ species were regarded as reaction intermediates after proton collision. Therefore, the latter dehydrogenation steps might be the rate-determining steps from the fact of this intermediate observation.

More detailed investigations for operando IR measurements were conducted to identify such $\mathrm{C}_{7} \mathrm{H}_{13}$ species as reaction intermediates. Fig. 5 portrays the time-course spectra of operando IR peaks after the electric field was applied and the MCH supply was turned off simultaneously. After 3-5 min with application of the electric field, peaks for the chemisorption
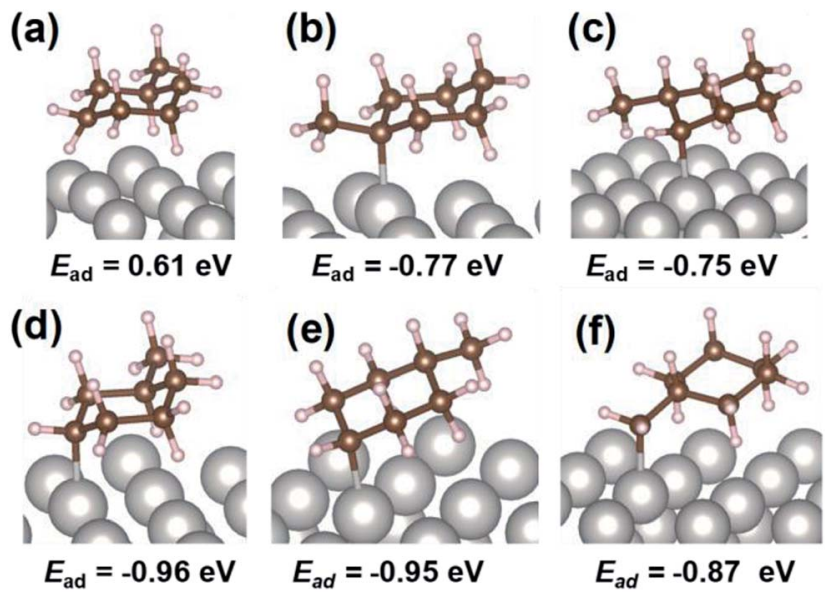

Fig. 4 Calculated optimized structure and adsorption energy with DFT calculation for $\mathrm{MCH}$ physisorption and $\mathrm{C}_{7} \mathrm{H}_{13}$ chemisorption at various positions: (a) MCH physisorption, (b) $\alpha$-position, (c) $\beta$-position, (d) $\gamma$-position, (e) $\delta$-position, and (f) methyl-group.

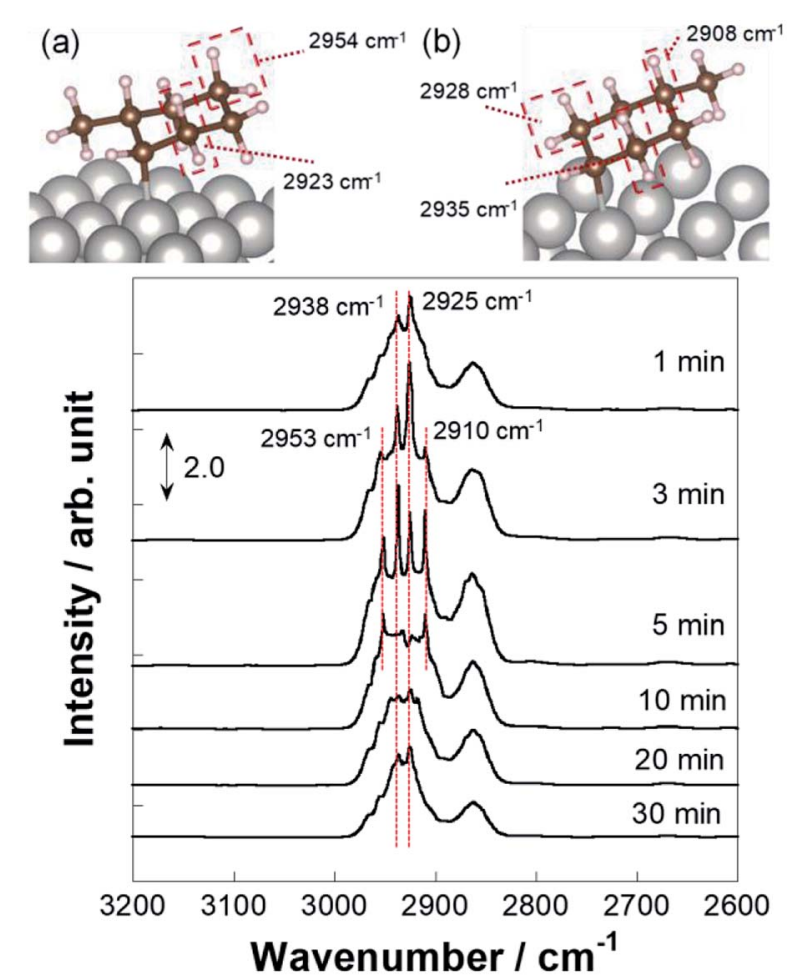

Fig. 5 Operando DRIFTS spectra for 3 wt $\% \mathrm{Pt} / \mathrm{CeO}_{2}$ with the electric field at $423 \mathrm{~K}$ with time course and theoretical identification of $\mathrm{C}-\mathrm{H}$ stretching for IR peaks of $\mathrm{C}_{7} \mathrm{H}_{13}$ chemisorbed at (a) $\beta$-position and (b) $\delta$-position based on DFT calculation.

were observed in addition to that of physisorption. Subsequently, at $10 \mathrm{~min}$, peak intensity for physisorption of $\mathrm{MCH}$ decreased faster than that of $\mathrm{C}_{7} \mathrm{H}_{13}$ chemisorption, which suggests that the second or third dehydrogenation was slower than the first dehydrogenation in the electric field. Then, the chemisorption peaks disappeared gradually within $30 \mathrm{~min}$. These physisorption peaks represented physisorbed $\mathrm{MCH}$ on inactive sites. Fig. 6 depicts the time-course spectra of operando IR without the electric field after the MCH supply was stopped. Contrary to the case with the electric field, MCH physisorption peaks were observed during IR measurement. Thereby, it can be surmised that the first dehydrogenation of $\mathrm{MCH}$ (cyclohexane to cyclohexene) was a reaction barrier or rate-determining step without the electric field..$^{54,55}$ Whereas the peak intensity for
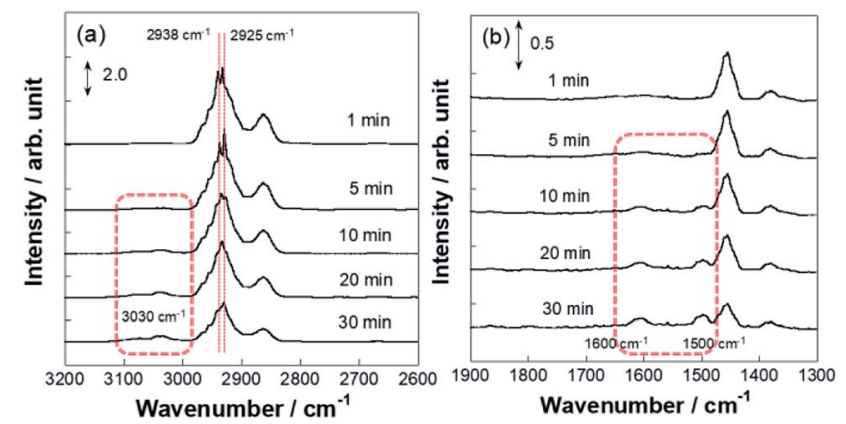

Fig. 6 Operando DRIFTS spectra for $3 \mathrm{wt} \% \mathrm{Pt} / \mathrm{CeO}_{2}$ without the electric field at $523 \mathrm{~K}$ with time course: wavenumber range (a) 2600$3200 \mathrm{~cm}^{-1}$ and (b) $1300-1900 \mathrm{~cm}^{-1}$. 
$\mathrm{MCH}$ physisorption decreased, that of toluene increased as measurements proceeded. These peaks were found for toluene: $\mathrm{C}-\mathrm{H}$ stretching at around $3030 \mathrm{~cm}^{-1}$ (Fig. S6 $\dagger$ ) and $\mathrm{C}-\mathrm{C}$ stretching at around 1500 and $1600 \mathrm{~cm}^{-1}$ were derived from dehydrogenation of $\mathrm{MCH} .^{52,53,56}$ Remarkably, toluene adsorption was not observed during the electric field application (Fig. 5) even though the conversions for two conditions were almost identical (with the electric field at $423 \mathrm{~K}$ and without the electric field at $523 \mathrm{~K}$ ).

\subsection{Reversibility of the reaction and the reaction mechanism}

Toluene hydrogenation reaction was conducted with the Pt/ $\mathrm{CeO}_{2}$ catalyst to assess the reversibility of the reaction because conversion of catalytic dehydrogenation of $\mathrm{MCH}$ with the electric field exceeded the calculated equilibrium, as shown in Table 1. Fig. 7 and Table S1† present temperature dependencies of toluene hydrogenation with and without the electric field. They show that hydrogenation activity with the electric field was lower than that without the electric field at temperatures below $523 \mathrm{~K}$. Toluene hydrogenation activity reached the equilibrium limit above $523 \mathrm{~K}$ because catalysis with heat is reversible. This reversible path is dominant at temperatures higher than $523 \mathrm{~K}$, irrespective of the reaction with/without the electric field. Suppressing catalytic activity for the reverse hydrogenation reaction with the electric field was observed. It derived from two reasons. First, as described above, the reactant toluene only slightly approached the reaction sites on $\mathrm{Pt} / \mathrm{CeO}_{2}$ because toluene can desorb easily by the application of the electric field. Additionally, it was difficult for the hydrogenation of adsorbed toluene to proceed because of proton conductivity ascertained from "inverse" kinetic isotopes. Proton hopping promoted $\mathrm{MCH}$ dehydrogenation through three-atom transition $\left(\mathrm{C}_{7} \mathrm{H}_{13}-\mathrm{H}-\right.$ $\left.\mathrm{H}^{+}\right) .{ }^{45}$ Consequently, hydrogenation with the electric field necessitated large apparent active energy and might be nearly

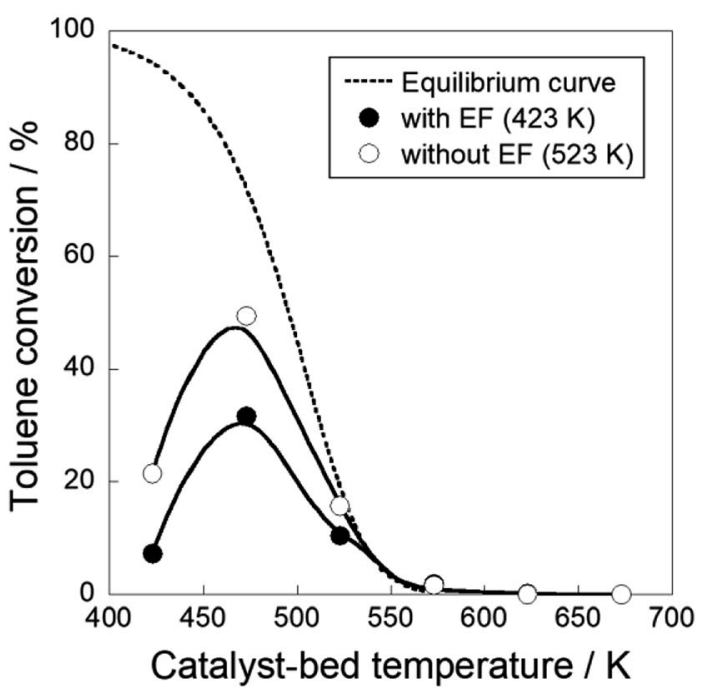

Fig. 7 Temperature dependencies of toluene hydrogenation on $3 \mathrm{wt} \%$ $\mathrm{Pt} / \mathrm{CeO}_{2}$ with and without the electric field: $423-673 \mathrm{~K}$ of reaction temperature; gas supply toluene : $\mathrm{H}_{2}: \mathrm{Ar}=6.4: 19.2: 10.8$ (total flow rate $56.4 \mathrm{~mL} \mathrm{~min}^{-1}$ ); $\mathrm{EF}$ : current $3 \mathrm{~mA}$.

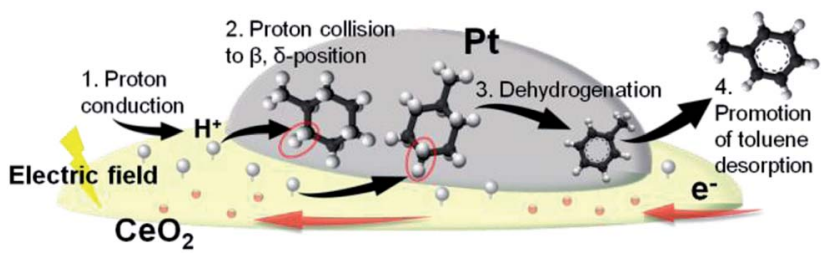

Fig. 8 Schematic illustration of $\mathrm{MCH}$ dehydrogenation in the electric field.

irreversible. ${ }^{45-47,49}$ This phenomenon is related to the effects of proton collision during $\mathrm{MCH}$ dehydrogenation. Therefore, the electric field application promoted dehydrogenation reaction with proton collision, and it inhibited reverse hydrogenation, then the dehydrogenation of $\mathrm{MCH}$ exceeds the equilibrium limitation by applying the electric field at low temperatures. Also, the catalytic dehydrogenation in the electric field showed stable activity (Table $\mathrm{S} 2 \dagger$ ) and no change for the catalyst structure was observed (Table $\mathrm{S} 3 \dagger$ ).

Fig. 8 presents the proposed reaction scheme according to the series of obtained results. We inferred that accelerated protons in the electric field (step 1) collided with $\mathrm{H}$ atoms of physisorbed $\mathrm{MCH}$ on either the $\beta$-position or $\delta$-position (step 2), which triggered the first dehydrogenation reaction of $\mathrm{MCH}$ (step 3). After subsequent dehydrogenation had proceeded, toluene desorption was also promoted with the electric field (step 4).

\section{Conclusions}

$\mathrm{MCH}$ dehydrogenation was conducted on $3 \mathrm{wt} \% \mathrm{Pt} / \mathrm{CeO}_{2}$ with the electric field application. High catalytic activity was obtained even at $423 \mathrm{~K}$, exceeding the equilibrium limitation. In the electric field, partial pressure dependence of $\mathrm{H}_{2}$ was found to be correlated positively with the reaction rate of dehydrogenation despite reversibility of the reaction. Furthermore, kinetic analyses revealed an "inverse" kinetic isotope effect (KIE). Proton acceleration that occurred along with the electric field application induced collisions with $\mathrm{H}$ atoms on $\mathrm{MCH}$, which advanced the dehydrogenation on $\mathrm{Pt} / \mathrm{CeO}_{2}$. According to operando IR measurements and DFT calculations, peculiar peaks were observed at wavenumbers of 2910 and $2953 \mathrm{~cm}^{-1}$ in the electric field. They were attributed to chemisorbed $\mathrm{C}_{7} \mathrm{H}_{13}$ species with $\beta$-position and $\delta$-position. Results demonstrate that protons collided with $\mathrm{H}$ atoms of $\mathrm{MCH}$ at such positions, and that $\mathrm{C}_{7} \mathrm{H}_{13}$ remained on the surface as the reaction intermediates. Although toluene adsorption was observed without the electric field, it was not confirmed with the electric field. Consequently, electric fields can also facilitate toluene desorption. Moreover, toluene hydrogenation (i.e. reverse reaction) was inhibited in the electric field. In conclusion, the electric field promoted $\mathrm{MCH}$ dehydrogenation with proton collision irreversibly, even at the low temperature of $423 \mathrm{~K}$.

\section{Conflicts of interest}

There are no conflicts to declare. 


\section{References}

1 S. Dutta, J. Ind. Eng. Chem., 2014, 20, 1148-1156.

2 Q.-L. Zhu and Q. Xu, Energy Environ. Sci., 2015, 8, 478-512.

3 E. Gianotti, M. Taillades-Jacquin, J. Roziere and D. J. Jones, ACS Catal., 2018, 8, 4660-4680.

4 Y. Okada, E. Sasaki, E. Watanabe, S. Hyodo and H. Nishijima, Int. J. Hydrogen Energy, 2006, 31, 1348-1356.

5 F. Alhumaidan, D. Cresswell and A. Garforth, Energy Fuels, 2011, 25, 4217-4234.

6 Y. Sugiura, T. Nagatsuka, K. Kubo, Y. Hirano, A. Nakamura, K. Miyazawa, Y. Iizuka, S. Furuta, H. Iki, T. Higo and Y. Sekine, Chem. Lett., 2017, 46, 1601-1604.

7 A. Nakano, S. Manabe, T. Higo, H. Seki, S. Nagatake, T. Yabe, S. Ogo, T. Nagatsuka, Y. Sugiura, H. Iki and Y. Sekine, Appl. Catal., A, 2017, 543, 75-81.

8 R. B. Biniwale, S. Rayalu, S. Devotta and M. Ichikawa, Int. J. Hydrogen Energy, 2008, 33, 360-365.

9 L. W. Jossens and E. E. Petersen, J. Catal., 1982, 73, 377-386. 10 M. A. Pacheco and E. E. Petersen, J. Catal., 1984, 86, 75-83. 11 M. A. Pacheco and E. E. Petersen, J. Catal., 1984, 88, 400-408.

12 M. Chai and K. Kawakami, J. Chem. Technol. Biotechnol., 1991, 51, 335-345.

13 J. F. Garcia de la Banda, A. Corma and F. V. Melo, Appl. Catal., 1986, 26, 103-121.

14 G. Maria, A. Marin, C. Wyss, S. Muller and E. Newson, Chem. Eng. Sci., 1996, 51, 2891-2896.

15 A. K. Pal, M. Bhowmick and R. D. Srivastava, Ind. Eng. Chem. Process Des. Dev., 1986, 25, 236-241.

$16 \mathrm{~J} . \mathrm{Yu}, \mathrm{Q}$. Ge, W. Fang and H. Xu, Int. J. Hydrogen Energy, 2011, 36, 11536-11544.

17 S. Nagatake, T. Higo, S. Ogo, Y. Sugiura, R. Watanabe, C. Fukuhara and Y. Sekine, Catal. Lett., 2016, 146, 54-60.

18 J. Yan, W. Wang, L. Miao, K. Wu, G. Chen, Y. Huang and Y. Yang, Int. J. Hydrogen Energy, 2018, 43, 9343-9352.

19 M. A. Pacheco and E. E. Petersen, J. Catal., 1985, 96, 507-516.

20 D. Teichmann, K. Stark, K. Muller, G. Zottl and P. Wasserscheid, Energy Environ. Sci., 2012, 5, 9044-9054.

21 G. W. H. Scherer and E. Newson, Int. J. Hydrogen Energy, 1998, 23, 19-25.

22 G. W. H. Scherer, E. Newson and A. Wokaun, Int. J. Hydrogen Energy, 1999, 24, 1157-1169.

23 G. Li, K. Yada, M. Kanezashi, T. Yoshioka and T. Tsuru, Ind. Eng. Chem. Res., 2013, 52, 13325-13332.

24 Y. R. Chen, T. Tsuru and D. Y. Kang, Int. J. Hydrogen Energy, 2017, 42, 26296-26307.

25 P. Ferreira-Aparicio, I. Rodriguez-Ramos and A. GuerreroRuiz, Chem. Commun., 2002, 2082-2083.

26 P. Ferreira-Aparicio, I. Rodriguez-Ramos and A. GuerreroRuiz, J. Catal., 2002, 212, 182-192.

27 J. K. Ali, E. J. Newson and D. W. T. Rippin, Chem. Eng. Sci., 1994, 49, 2129-2134.

28 J. K. Ali and A. Baiker, Appl. Catal., A, 1997, 155, 41-57.

29 K. Oda, K. Akamatsu, T. Sugawara, R. Kikuchi, A. Segawa and S. Nakao, Ind. Eng. Chem. Res., 2010, 49, 11287-11293.
30 S. Hodoshima, H. Arai and Y. Saito, Int. J. Hydrogen Energy, 2003, 28, 197-204.

31 S. Hodoshima, S. Takaiwa, S. Shono, K. Satoh and Y. Saito, Appl. Catal., A, 2005, 283, 235-242.

32 C. Shinohara, S. Kawakami, T. Moriga, H. Hayashi, S. Hodoshima, Y. Saito and S. Sugiyama, Appl. Catal., A, 2004, 266, 251-255.

33 D. Sebastian, E. G. Bordeje, L. Calvillo, M. J. Lazaro and R. Moliner, Int. J. Hydrogen Energy, 2008, 33, 1329-1334.

34 Y. Saito, K. Aramaki, S. Hodoshima, M. Saito, A. Shono, J. Kuwano and K. Otake, Chem. Eng. Sci., 2008, 63, 49354941.

35 N. Kariya, A. Fukuoka and M. Ichikawa, Appl. Catal., A, 2002, 233, 91-102.

36 A. A. Shukula, P. V. Gosabi, J. V. Pande, V. P. Kumar, K. V. R. Chary and R. B. Biniwale, Int. J. Hydrogen Energy, 2010, 35, 4020-4026.

37 R. Manabe, S. Okada, R. Inagaki, K. Oshima, S. Ogo and Y. Sekine, Sci. Rep., 2016, 6, 38007.

38 R. Inagaki, R. Manabe, Y. Hisai, Y. Kamite, T. Yabe, S. Ogo and Y. Sekine, Int. J. Hydrogen Energy, 2018, 43, 14310-14318.

39 K. Oshima, T. Shinagawa, Y. Nogami, R. Manabe, S. Ogo and Y. Sekine, Catal. Today, 2014, 232, 27-32.

40 T. Yabe, Y. Kamite, K. Sugiura, S. Ogo and Y. Sekine, J. CO2 Util., 2017, 20, 156-162.

41 Y. Sekine, M. Haraguchi, M. Tomioka and E. Kikuchi, J. Phys. Chem. A, 2010, 114, 3824-3833.

42 S. Ogo and Y. Sekine, Chem. Rec., 2017, 17, 726-738.

43 K. Oshima, T. Shinagawa, M. Haraguchi and Y. Sekine, Int. J. Hydrogen Energy, 2013, 38, 3003-3011.

44 Y. Sekine, M. Haraguchi and E. Kikuchi, Catal. Today, 2011, 171, 116-125.

45 S. Okada, R. Manabe, R. Inagaki, S. Ogo and Y. Sekine, Catal. Today, 2018, 307, 272-276.

46 G. C. Schatz and A. F. Wagner, J. Phys. Chem., 1984, 88, 221232.

47 M. J. Kurylo, G. A. Hollinden and R. B. Timmons, J. Chem. Phys., 1970, 52, 1773-1781.

48 K. B. Wiberg, Chem. Rev., 1955, 55, 713-743.

49 B. Kerkeni and D. C. Clary, J. Phys. Chem. A, 2004, 108, 89668972.

50 G. A. Olah and R. H. Schlosberg, J. Am. Chem. Soc., 1968, 90, 2726-2727.

51 G. A. Olah, G. Klopman and R. H. Schlosberg, J. Am. Chem. Soc., 1969, 91, 3261-3268.

52 D. Murzin, T. Salmi, S. Smeds, M. Laatikainen, M. Mustonen and E. Paatero, React. Kinet. Catal. Lett., 1997, 61, 227-236.

53 M. D. Hernandez, I. Tejedor-Tejedor, J. M. Coronado and M. A. Andreson, Appl. Catal., B, 2011, 101, 283-293.

54 P. A. V. Trimpont, G. B. Marin and G. F. Froment, Ind. Eng. Chem. Fundam., 1986, 25, 544-553.

55 F. Alhumaidan, D. Cresswell and A. Garforth, Ind. Eng. Chem. Res., 2011, 50, 2509-2522.

56 K. Takise, T. Higo, D. Mukai, S. Ogo, Y. Sugiura and Y. Sekine, Catal. Today, 2016, 265, 111-117. 